\title{
COMPARATIVE STUDY TO THE EFFECT OF NATURAL INTERCOURSE VERSUS SYNTHETIC PROSTAGLANDIN ON INTRAUTERINE INSEMINATION
}

\author{
Nassar A. M. ${ }^{(1,2,3)}$, El Safoury $T^{(3)^{*}}$, Shaeir M. Z..$^{(3)^{*}}$, \\ Anwar E. (2)* \& Mehanna A. (2)* \\ (1) Department of Obstetrics \& Gynecology, International Islamic Center \\ for Population Studies and Research (IICPSR), Al Azhar University \\ (2) ART Unit, IICPSR, Al Azhar University; \\ (3) Kamal Shaeir IVF Center, Giza, Egypt. \\ * Embryologist
}

\section{ABSTRACT}

\begin{abstract}
Objectives : Our objective was to evaluate the effect of natural source of Prostaglandin in seminal fluid through natural intercourse versus synthetic Prostaglandin (Misoprostol $400 \mu \mathrm{g}$ ) Vaginal tablets on the outcome of intra-uterine insemination (IUI) when used 24 hours following insemination.
\end{abstract}

Design : A prospective randomized controlled study.

Setting : This study was carried out at Al-Azhar ART uint in IICPSR and Kamal Shacir IVF center along a period started November 2001 to July 2004.

Patients \& methods : Eighty six women complaining of primay infertility, their age ranged between 25 and 35 years and BMI less than $28 \mathrm{~kg} / \mathrm{m}^{2}$ undergoing intrauterine Insemination due to male subfertility, were recruited to the study. They were randomly allocated into three groups according to the adjunctive method used for them: Group I: 28 patients exposed to a single insemination set (control), Group-II 31 patients exposed to a single insemination set as well as applying an intravaginal misoprostol (400 ug) tablet 12 hours later and Group-III : 27 paticnts exposed to a single insemination set and instructed to do natural intercourse 12 hours later. All patients were subjected to controlled ovarian hyper stimulation $(\mathrm{COH})$ using clomiphenc citrate 100 mg/day on days 3-7 and hMG 75 mIU IM daily injection from day 6 until the day of hCG. Then IUI was done 36 to 40 hours from hCG IM injection (10.000 IU) and luteal phase support until quantitative $\beta$-hCG test.

Results : According to the outcome in this study, the pregnancy rate per patient was $10.7 \%, 19.3 \%$ and $14.8 \%$ in the three groups respectively. The pregnancy rate per cyclc was $3.6 \%, 6.8 \%$ and $5.2 \%$ in the studicd groups respectivley.

Conclusion : Prostaglandin has an active role in improving the pregnancy rate in IUI treated cycles whatever its source used (seminal or synthetic) as an adjunctive support. This could be either through improving uterine contractiltiy and tubal peristaltic movement during sperm migration or by improving the endometrial receptivity.

\section{INTRODUCTION}

Prostaglandin increases myometrial contractility and isthmic tubal relaxation, affects luteal maintenance, immunosuppression and enhances spermoocyte interaction as well as all the properties that may account for their fertility-enhancing effect ${ }^{(1)}$.
Human semen contains large amounts of prostaglandins, the main source being the seminal vesicles ${ }^{(2)}$. It has been suggested that there is a link between prostaglandin and fertility, since its lower concentrations were found in the seminal fluid of men from infertile couples ${ }^{(3)}$.

Prostaglandins increase myometrial contractility 
and isthmic tubal relaxation, affect luteal maintenance, immunosuppression and enhance spermatozoon-oocyte and all propeerties that may account for their fertility-enhancing effects ${ }^{(4)}$

Intrauterine insemination (IUI) has an important role in the treatment of a considerable sector of infertile couples due to mild to moderate oligoasthienospermia, hostile cervix and unexplained infertility ${ }^{(5)}$.

Misoprostol is a commercially available synthetic $P G$ that is structurally related to PGEI and was used initially to prevent peptic ulcer disease induced by chronic ingestion of non-steroidal anti-inflammatory drugs. It has also been used extensively as an orally and intravaginal medication for termination of pregnancy and also in medical induction of labor ${ }^{(6)}$.

\section{AIM OF THE WORK}

To assess the role of the natural versus synthetic prostaglandin as an adjunctive supportive material to the procedure of IUI. This include application of prostaglandins 12 hours after IUI either through natural intercourse (seminal fluid) or vaginal Misoprostol $400 \mu \mathrm{g}$ vaginal tablets.

\section{MATERIALS \& METHODS}

Eighty six infertile women presenting to $\mathrm{Al}$ Azhar ART Unit in the International Islamic Center for Population Studies and Research at Al-Azhar University and Kamal Shaeir IVF center between November 2001 to July 2004. They were offered study entry when diagnosed as primary infertility only due to male subfertility.

Male subfertility diagnosis was classified as male factor if semen analysis revealed oligozoospermia (sperm concentration $<20$ millions spermatozoa $/ \mathrm{ml}$ ) asthenozoospermia (< $30 \%$ progressively motile sperms) and /or teratospermia (Abnormal forms $>40 \%$ ). Female partners were submitted for compelte infertility work up. Women diagnosed as dysovulatory, PCO, endometriosis and peritubal adhesion were excluded from the study.

All women were randomly dividied into three groups according to the adjunctive method used for them: Group (I): 28 patients exposed only to a single insemination set (control group), Group (II): 31 patients exposed to a single insemination set followed by insertion of Misoprostol ( $400 \mu \mathrm{g})$ vaginal tablets 12 hours later and Group (III): 27 patients exposed to a single insemination set with Instruction to do natural intercourse 12 hours later. For those who did not achieve pregnancy, a maximum of three treatment cycles were tried in each group. Subjects wer instructed to avoid coitus from 72 hours before expected insemination. Written consent was fulfilled for all cases.

All patients wre subjected to controlled ovarian hyper stimulation $(\mathrm{COH})$ using clomiphene citrate $100 \mathrm{mg} /$ day given on cycle days 3-7 and $\mathrm{hMG}$ $75 \mathrm{IU}$ IM injection on day $6-9$ or more to be handled according to the ultrasonic follicular monitoring. Ovulation was trigered by i.m. injection of $10000 \mathrm{IU}$ of hCG when the leading follicle(s) reached a diameter of $18-20 \mathrm{~mm}$. IUI was then performed $36-38$ hours later.

Semen samples for IUI were collected and prepared by sperm washing technique, and with further processing by the use of gradient centrifugation.

IUI was performed using intrauterine insemination catheter. Patients remained supine for 15 min after IUI. 
All patients have had luteal support by oral progesterone tablets (utrogestan ${ }^{(B)}$ ) $200 \mathrm{mg}$ twice daily starting 48 hours post insemination. Luteal support was continued until serum pregnancy evaluation - 16 days after insemination, and when pregnant, luteal support continued until gestational week 10 .

Pregnancy determinations were made by serum hCG titre evaluation. Positive tests were further followed by transvaginal ultrasonography at two to three weeks from the pregnancy test. Those with gestational sac and positive cardiac pulsations were defined as clinical pregnancies.

All data collected were statistically analysed.

\section{RESULTS}

Comparisons of demographic variables between the three studied groups are shown in Table (I). No significant differences were noted between them.
In all studied groups the semen parameters of all male partners showed non-significant differences as shown in Table (II).

In total 86 women were recruited to the study, entailing 247 IUI cycles that resulted in a total of 13 pregnancies $(5.3 \%)$. None supported (control) groupe totalled 82 cycles and 3 pregnancies $(3.6 \%$ per treated cycle), whereas misoprostol cycles totalled 88 with 6 pregnancies $(6.88 \%$ per treated cycle), while the natural intercourse group totalled 77 cycles with 4 pregnancies (5.2\% per treated) cycle. The estimated pregnancy rates per individual treatment cycle were listed in Table (III) that shows occurrence of pregnancy in all studdied groups with an increasing chances of getting pregnancy in the subsequent trials.

Pregnancy rates per cycle for those who used Misoprostol was the highest, Table (III) and (IV) followed by those in group III (natural intercourse)

Table I : Patients characteristics in studied groups.

\begin{tabular}{|l|c|c|c|c|}
\hline & G.I $\mathbf{n = 2 8}$ & G.II $\mathbf{n = 3 1}$ & G.III $\mathbf{n = 2 7}$ & P \\
\hline Age & $29.4 \pm 4.9$ & $30.5 \pm 5.9$ & $31.2 \pm 3.4$ & NS \\
\hline Infertilityduration (years) & $4.6 \pm 2.4$ & $5.4 \pm 2.8$ & $4.4 \pm 3.12$ & NS \\
\hline BMI & $25.72 \pm 2.54$ & $27.01 \pm 1.54$ & $26.33 \pm 2.8$ & NS \\
\hline
\end{tabular}

$\mathrm{P}>0.05$

Table II : Mean and SD of semen parameters in studied groups .

\begin{tabular}{|l|c|c|c|c|}
\hline & G.I $\mathbf{n = 2 8}$ & G.II $\mathbf{n = 3 1}$ & G.III $\mathbf{n = 2 7}$ & $\mathbf{P}$ \\
\hline Count million/mL & $13.3 \pm 5.31$ & $14.7 \pm 6.51$ & $15.3 \pm 3.83$ & NS \\
\hline Forward progressive \% & $20.6 \pm 14.4$ & $18.6 \pm 6.6$ & $19.71 \pm 4.4$ & NS \\
\hline Abnormal forms \% & $33.63 \pm 18.14$ & $40.4 \pm 13.1$ & $34.53 \pm 13.6$ & NS \\
\hline
\end{tabular}

$P>0.05$ 
Table III : Outcome according to the different methods used in each treatment cycled.

\begin{tabular}{|c|c|c|c|}
\hline & G.I $\quad n=28$ & G.II $\quad \mathrm{n}=\mathbf{3 1}$ & G.III $\quad n=27$ \\
\hline Cycle I & $1 / 28$ & $2 / 31$ & $1 / 27$ \\
\hline Preg. n-\% & $3.6 . \%$ & $6.4 \%$ & $3.7 \%$ \\
\hline Cycle II & $0 / 27$ & $1 / 29$ & $2 / 26$ \\
\hline Preg. n-\% & $0 \%$ & $3.4 \%$ & $7.7 \%$ \\
\hline Cycle III & $2 / 27$ & $3 / 28$ & $1 / 24$ \\
\hline Preg. n-\% & $7.1 \%$ & $10.7 \%$ & $4.2 \%$ \\
\hline
\end{tabular}

Table IV : Cumulative pregnancy rate per patient and per cycle.

\begin{tabular}{|c|c|c|c|c|}
\hline & G.I $n=28$ & G.II $\quad n=31$ & G.III $\quad n=27$ & $\mathbf{P}$ \\
\hline Pregnancy ratio & \multirow{2}{*}{$\begin{array}{c}3 / 28 \\
10.7 \%\end{array}$} & \multirow{2}{*}{$\begin{array}{c}6 / 31 \\
19.3 \% \\
\end{array}$} & \multirow{2}{*}{$\begin{array}{c}4 / 27 \\
14.8 \%\end{array}$} & 86 \\
\hline per patient & & & & patients \\
\hline Pregnancy ratio per & $3 / 82$ & $6 / 88$ & $4 / 77$ & 247 \\
\hline treatment cycle & $3.6 \%$ & $6.8 \%$ & $5.2 \%$ & cycles \\
\hline
\end{tabular}

\section{DISCUSSION}

Intrauterine insemination is a line of treatment for a large number of infertile couples due to male subfertility, hostile cervix and unexplained infertility. So many researchers are trying to improve the outcome of such a simple and economic technique.

In this study, male subfertility was selected as a single factor for study entry to overcome biased results.

Of all body fluids, human seminal plasma possesses the highest concentration of $\mathrm{PG}{ }^{(7)}$. PGs are known to enhance sperm transport and increase the fertilization rate in rabbits. Animal studies involving the use of intrauterine PGE infusion have resulted in the maintenance of corpora luteal function and stimulation of progesterone production, ensuring uterine receptivity for pregnancy ${ }^{(4)}$.

Human in-vitro research has shown that PGE induces a relaxation response on the non-pregnant human uterine and Fallopian tube smooth, muscle whereas PGF has been shown in vitro to create a contractile response. The in-vivo effects from both PG are stimulatory on the myometrium (8). Moreover, it has also been shown that PGE is more potent than PGF on myometrial response and that both PG inhibit tubal motility, thus suggesting that the relaxation of the tubal isthmus is a prerequisite for sperm penetration into the Fallopian tubes (11). Additional effects such as immuno-suppression afforded by seminal PG has been shown both in vivo and in vitro, suggesting an attenuated female Immunological response to spermatozoa ${ }^{(9)}$.

In this work we studied the effect of 
prostaglandin application 12 hours after insemination on the outcome. This application was applied either through natural sexual intercourse (natural prostaglandin in the seminal fluid) or by vaginal application of misoprostol tablets $(400 \mu \mathrm{g})$.

As a regard to patients characteristics the relation was statistically insignificant between the three groups regarding thier age, duration of infertility and Body Mass Index (Tab. I).

In view of semen parameters (count, progressive motility and abnormal forms) there was no statistical significant relationship between the three groups (Tab. II).

According to the outcome, the pregnancy rate/patient was $10.7 \%, 19.3 \%$ and $14.8 \%$ in the three groups respectively. As regards the pregnancy rate per treated cycle it was $3.6 \%, 6.8 \%$ and $5.2 \%$ respectively.

So, from the previous data we found that there was a notable improvement in IUI outcome when accompanied by prostaglandin application either naturally or synthetic, but of better results with the synthetic type.

These results were in agreement with (1) who postulated a significant improvement in the ability of human spermatozoa to penetrate zona-free hamster oocytes, in the presence of prostaglandin $\mathrm{E}_{2}$.

The results of this study goes with the suggestion of Bygdeman and his Colleagues that there is a link between prostaglandin and infertility where they found a low concentration of prostaglandins in the seminal fluid of infertile males.

Brown and others in (2001) ${ }^{(10)}$ reported that application of misoprostol vaginally may improve the chances for pregnancy in women having IUI in a wide variety of cycle types and this is in agreement with the result of the current study.

The positive effect of vaginal misoprostol leading to an improved clinical pregnancy rate is not clearly understood. However, a casual link remains to be established and further studies are needed to determine the precise role of prostaglandine in early human reproduction.

\section{CONCLUSIONS}

Prostaglandin has an active role in improving the IUI outcome either through improving uterine contractility and tubal peristalsis movement during sperm migration or improving endometrial rceptivity. Whatever was the source of prostaglandin used as adjunctive supportive material (natural or synthetic) a notable improvement in pregnancy rate had been occurred as been observed in this study.

\section{REFERENCES}

I- Aitken, R. J. and Kelly, R. W. : Analysis of the direct effects of prostaglandins on human sperm function. $J$ reprod. Fert., 1985; 73, 139-146.

2- Gottlieb, C., Plonen, L., Kvist, U et al.: The infertility potential of male cystic fibrosis patients. Int. J. Androl., 1991; 14, 437-440.

3- Bygdeman, M., Fredricsson, B., Svanborg, K. et al.: The relation between fertility and prostaglandin content of seminal fluid in man. Fert. Steril.,1970; $21,622-629$.

4- Thibodeaux, J. K., Myers, M. W., Roussel,. J. D. : Intrauterin infusion of prostaglandin E2 and subsequent luteal function in cattle. Prostaglandins, $1978 ; 44,5531-5541$.

5- Oehninger, S., Franken, D. and Kruger, T.: Approaching the next millennium: how should we manage andrology diagnosis in the intracytoplasmic injection cra? (editorial). Fert. Steril., 1997; 67, 434-436. 
6- Creinin, M. D. and Darney, P. D.: Methotrexate and misoprostol for early abortion (published erratum appears on Contraception, 49, 99 (1994). Contraception, 1993; 48, 339-348.

7- Mann, $T$ and Lutwak-Mann, C.: Biochemistry of seminal plasma and male accessory fluids. In: Male Reproductive Function and Semen Springer-Verlage, Neo York, 1981; pp. 312-463.

8- Coutinho, E. M. and Maia, H. S.: The contractile response of the human uterus, fallopian tubes and ovary to prostaglandins in vivo. Fertil. Steril., 1971; $22,539-543$.
9- Skibinski, G., Kelly, R. W., Harrison, C. M. et al.: Relative immunosuppressive activity of human seminal prostaglandins. L. Reprod. Immunol., $18=992 ; 22,185-195$.

10- Brown S. E., James P. Toner, and Sergio Oehninger.: Vaginal misoprostol enhances intrauterine insemination. Human Reproduction 2001; Vol. 16, Np. pp. 96-101.

11- Jubbour H. N. and Boddy S. C.; : Prostaglandin E2 induces proliferation of glandular epithelial cells of the human endometrium., J. Clin. Endocrinol \& Metabol., 2003; mvol. 88, 9; 4481-4487. 